\title{
Evident bacterial community changes but only slight degradation when polluted with pyrene in a red soil
}

\author{
Gaidi Ren, Wenjie Ren, Ying Teng* and Zhengao Li \\ Key Laboratory of Soil Environment and Pollution Remediation, Institute of Soil Science - Chinese Academy of Sciences, Nanjing, China
}

\section{Edited by:}

Paul Bodelier, Netherlands Institute of Ecology - Royal Netherlands Academy of Arts and Sciences, Netherlands

\section{Reviewed by:}

Kim Yriälä, University of Helsinki, Finland

Thorunn Helgason, University of York, UK

\section{*Correspondence:}

Ying Teng, Key Laboratory of Soil Environment and Pollution

Remediation, Institute of Soil Science - Chinese Academy of Sciences, East Beijing Road No. 71 , Nanjing 210008, China

e-mail: yteng@issas.ac.cn
Understanding the potential for Polycyclic aromatic hydrocarbons (PAH) degradation by indigenous microbiota and the influence of PAHs on native microbial communities is of great importance for bioremediation and ecological evaluation. Various studies have focused on the bacterial communities in the environment where obvious PAH degradation was observed, little is known about the microbiota in the soil where poor degradation was observed. Soil microcosms were constructed with a red soil by supplementation with a high-molecular-weight PAH (pyrene) at three dosages (5, 30, and $70 \mathrm{mg} \cdot \mathrm{kg}^{-1}$ ). Real-time PCR was used to evaluate the changes in bacterial abundance and pyrene dioxygenase gene (nidA) quantity. Illumina sequencing was used to investigate changes in diversity, structure, and composition of bacterial communities. After 42 days of incubation, no evident degradation was observed. The poor degradation ability was associated with the stability or significant decrease of abundance of the nidA gene. Although the abundance of the bacterial 16S rRNA gene was not affected by pyrene, the bacterial richness and diversity were decreased with increasing dosage of pyrene and the community structure was changed. Phylotypes affected by pyrene were comprehensively surveyed: (1) at the high taxonomic level, seven of the abundant phyla/classes (relative abundance $>1.0 \%$ ) including Chloroflexi, AD3, WPS-2, GAL5, Alphaproteobacteria, Actinobacteria, and Deltaproteobacteria and one rare phylum Crenarchaeota were significantly decreased by at least one dosage of pyrene, while three phyla/classes (Acidobacteria, Betaproteobacteria, and Gammaproteobacteria) were significantly increased; and (2) at the lower taxonomic level, the relative abundances of twelve orders were significantly depressed, whereas those of nine orders were significantly increased. This work enhanced our understanding of the biodegradation potential of pyrene in red soil and the effect of pyrene on soil ecosystems at the microbial community level.

Keywords: PAH pollution, pyrene, biodegradation, bacterial community, 16S rRNA gene, Illumina sequencing, red soil

\section{INTRODUCTION}

Polycyclic aromatic hydrocarbons (PAHs) composed of two or more fused aromatic rings are one of the most prevalent groups of organic contaminants in soil. Due to their persistence and toxicity, PAHs have become a substantial threat to the stability and function of soil ecosystems. Increased anthropogenic activities such as the combustion of wood, coal and petroleum and mining accidents have dramatically exacerbated soil pollution with PAHs. Microorganisms play a critical role in PAH transformation and degradation in terrestrial ecosystems because microbial degradation is the principal process underlying natural decontamination (Viñas et al., 2005). Under conditions of long-term PAH pollution, some native adapted microorganism may be able to utilize the bio-available PAHs as their sole carbon or energy source, resulting in the degradation of PAHs in situ. Some PAH-degradative populations have been isolated and characterized using culturedependent methods (Heitkamp etal., 1988; Masakorala et al., 2013; Ping etal., 2014; Yuan etal., 2014); these populations are frequently affiliated with a limited number of taxonomic groups such as Sphingomonas, Burkholderia, Pseudomonas, Rhodococcus, and Mycobacterium (Uyttebroek et al., 2006). Molecular ecological approaches have also been developed to study $\mathrm{PAH}$-degradative bacterial populations. For example, a previous study (DeBruyn et al., 2009) evaluated the potential for PAH biodegradation by indigenous microbial communities through the detection and quantification of a key PAH-degradative gene (pyrene dioxygenase gene: nidA). The authors found that pyrene-degrading Mycobacterium showed a broad geographical distribution and may play an important role in the natural attenuation and cycling of PAHs in Lake Erie.

The biodegradation of PAHs is influenced by several biotic (Sipilä etal., 2008) and abiotic (Simarro etal., 2011) factors. The type of PAH (Singleton et al., 2005; DeBruyn et al., 2011), plant exudate (Sipilä et al., 2008) and size fractions of the soil (Uyttebroek etal., 2006) have been shown to influence the composition and abundance of total or degradative bacterial populations in polluted soil. Therefore, PAHs may not always be degraded by native microorganisms, especially in soils that have not experienced historical PAH contamination, although there are reports of PAH degradation in soils without historical 
PAH contamination (Tervahauta et al., 2009; Yrjälä et al., 2010). The microbial populations in polluted soil or sediments have been well studied, but the PAH degradation potential exhibited by indigenous microbiota and microbial community changes in unpolluted soils threatened with $\mathrm{PAH}$ pollution are not well understood.

Several possibilities may occur when unpolluted soil suffers from $\mathrm{PAH}$ pollution. Some microbial populations may adapt rapidly to pollution and use the PAHs as carbon or energy sources for survival, leading to degradation. In contrast, the PAHs may exert toxic effects on the microorganisms where biodegradation does not occur, resulting in the loss of microbial diversity. Some populations may again not suffer from toxic effects, but are also not degraders of PAHs (Mukherjee et al., 2013, 2014). Various studies have focused on the $\mathrm{PAH}$ degrading bacteria and the total bacterial communities in the environments where obvious degradation was observed (Peng et al., 2010; Singleton et al., 2013; Sauret et al., 2014; Sun et al., 2014), little is known about the relationship between the degradation and the PAH degrading bacterial populations and influence of $\mathrm{PAH}$ on the microbial community in the case where $\mathrm{PAH}$ degradation did not happen. Red soils are widely distributed in China, covering more than $20 \%$ of the country's total land area and constituting one of the most important soil sources for food production (Huang and Zhao, 2014). Understanding the relationship between PAH degradation potential and the associated microbial community changes is important for ecological evaluation of the effect of PAHs on soil ecosystems from the viewpoint of microbial ecology. Furthermore, increased understanding is a prerequisite for directing the management and cleanup of PAH-contaminated soil ecosystems.

Soil is considered to be a highly complex system with an overwhelming diversity of bacterial communities. It is estimated that a typical gram of soil contains one billion bacterial cells and thousands to millions of bacterial species (Gans et al., 2005). Therefore, some conventional molecular biology approaches such as terminal restriction fragment length polymorphism (T-RFLP), denaturing gel gradient electrophoresis (DGGE), and 16S rRNAbased clone library construction may not be sensitive enough to resolve the changes caused by $\mathrm{PAH}$ pollution at the microbial community level because of the lower resolution of these techniques. The advent of next generation sequencing techniques have opened new frontiers in microbial community analysis by providing unprecedented levels of coverage and resolution of the microbial community because this technique can generate millions to billions of sequence reads in a single run (Huse et al., 2008; Hollister etal., 2010). These techniques have been used to identify the bacterial populations that are correlated with PAH degradation (Singleton et al., 2011; Kawasaki et al., 2012; Sun et al., 2014), evaluate the bacterial community changes during the bioremediation process of PAH polluted soil (Kawasaki et al., 2012; Singleton et al., 2013), assess the association between the spatial patterns of bacterial diversity and the distribution of pollutants [including PAHs and total hydrocarbons (C10-C40)] (Mukherjee et al., 2014), as well as to determine the complete genomic sequences of PAH degradation strains (Jin et al., 2011; Zhang et al., 2012).
In this study, microcosm incubation experiment was performed with an unpolluted red soil by supplementation with a highmolecular-weight PAH (pyrene). Illumina sequencing and realtime PCR techniques were used to investigate the bacterial community changes. Of particular interest are (1) whether the native bacterial community can adjust in a short time leading to the degradation of pyrene, (2) how the bacterial community is adjusting to additions of pyrene to clean soil, and (3) how the fate of added pyrene can be explained by combining bacterial community analysis and real-time PCR of the nidA gene.

\section{MATERIALS AND METHODS SITE DESCRIPTION AND SOIL SAMPLING}

The red soil was collected from surface soil at a depth of $0-15 \mathrm{~cm}$ from a long-term field experiment station in Yingtan, Jiangxi province, China $\left(28^{\circ} 15^{\prime} 30^{\prime \prime} \mathrm{N}, 116^{\circ} 55^{\prime} 30^{\prime \prime} \mathrm{E}\right)$. The soil was passed through a $2 \mathrm{~mm}$ mesh to remove stones and plant debris and stored at $4^{\circ} \mathrm{C}$ before the batch experiment. The soil properties were as follows: $\mathrm{pH}\left(\mathrm{H}_{2} \mathrm{O}\right) 4.51$, organic matter $6.60 \mathrm{~g} \cdot \mathrm{kg}^{-1}$, total $\mathrm{N} 0.39 \mathrm{~g} \cdot \mathrm{kg}^{-1}$, total P $0.015 \mathrm{~g} \cdot \mathrm{kg}^{-1}$, total $\mathrm{K} 8.54 \mathrm{~g} \cdot \mathrm{kg}^{-1}$, available $\mathrm{N} 40.8 \mathrm{mg} \cdot \mathrm{kg}^{-1}$, available $\mathrm{P} 1.33 \mathrm{mg} \cdot \mathrm{kg}^{-1}$, available $\mathrm{K} 47.0 \mathrm{mg} \cdot \mathrm{kg}^{-1}$, and cation exchange capacity (CEC) $9.06 \mathrm{cmol} . \mathrm{kg}^{-1}$. The initial total concentration of 16 USEPA PAHs ( $\Sigma$ PAHs) was $38.4 \mu \mathrm{g} \cdot \mathrm{kg}^{-1}$ soil (on dry weight soil, i.e., d.w.s.); the initial concentration of pyrene was $10.3 \mu \mathrm{g} \cdot \mathrm{kg}^{-1}$ d.w.s.. This indicated that the tested soil was not polluted with PAHs as the soils with content of $\Sigma$ PAHs $<200 \mu \mathrm{g} \cdot \mathrm{kg}^{-1}$ are classified as non-contaminated soils (Maliszewska-Kordybach, 1996).

\section{MICROCOSM EXPERIMENT}

Prior to the microcosm experiment the soils were kept at $28^{\circ} \mathrm{C}$ for 1 week to equilibrate. Pyrene stock solutions (500, 3,000, and $7,000 \mathrm{mg} \cdot \mathrm{L}^{-1}$ ) were prepared by dissolving the chemical in acetone. Pyrene-treated soils at concentrations of 5, 30, and $70 \mathrm{mg} \cdot \mathrm{kg}^{-1}$ d.w.s. were included in this microcosm experiment. The details of the soil contamination with pyrene were as follows: $25 \mathrm{~g}$ of soil (based on dry soil weight) were used as seedling soils for each treatment and were contaminated by spiking with $2.5 \mathrm{~mL}$ of the $500,3,000$, and $7,000 \mu \mathrm{g} \cdot \mathrm{ml}^{-1}$ pyrene stock solutions to reach final concentrations of 50,300 , and $700 \mathrm{mg} \cdot \mathrm{kg}^{-1}$ d.w.s. Soil spiked with $2.5 \mathrm{~mL}$ of acetone was used as seedling soil for the control (CK). All seedling soils were kept in a chemical hood overnight to allow the acetone to evaporate. The seedling soil was added to 225 g natural soil (based on dry weight) and mixed thoroughly to achieve final targeted pyrene concentrations of 5, 30, and $70 \mathrm{mg} \cdot \mathrm{kg}^{-1}$ d.w.s. After contaminating with pyrene, $10 \mathrm{~g}$ of soil (based on dry weight) for each treatment were aliquoted into $120 \mathrm{~mL}$ serum bottles; sterilized water was added to adjust the water content to $60 \%$ of the SWHC (soil water holding capacity). The bottles were capped with black butyl stoppers, and the microcosms were incubated at $28^{\circ} \mathrm{C}$ in darkness for 42 days. On days $0,4,7,14,21,28$, and 42 , triplicate samples from each pyrene-spiked sample were collected for further pyrene analysis or DNA extraction. The headspace of the other bottles was flushed with synthetic air $\left(20 \% \mathrm{O}_{2}\right.$ and $\left.80 \% \mathrm{~N}_{2}\right)$ for $45 \mathrm{~s}$ after sampling on days $7,14,21,28$, and 42 to maintain oxic conditions. 


\section{PYRENE EXTRACTION AND DETERMINATION}

Pyrene in soil was extracted and purified according to the method described in previous studies (Qian et al., 2007; Mao et al., 2012) with slight modifications. Specifically, soil samples were freezedried with a vacuum freeze drier and passed through a $0.250 \mathrm{~mm}$ mesh. Then, $2 \mathrm{~g}$ of soil was Soxhlet-extracted with $70 \mathrm{~mL}$ of dichloromethane for $24 \mathrm{~h}$. The extract solution was rotary evaporated. The residue was dissolved in $2 \mathrm{~mL}$ of cyclohexane; next, $0.5 \mathrm{~mL}$ of the solute was transferred and purified using a silica gel column $(8 \times 220 \mathrm{~mm})$ and washed with a mixture of hexane and dichloromethane $(1: 1, \mathrm{v} / \mathrm{v})$. The first $1 \mathrm{~mL}$ of the eluate was discarded because it contained non-polar compounds such as saturated hydrocarbons and showed weaker retention than PAHs in silica gel. The second 2-mL aliquot of eluate was collected, evaporated to dryness under a $\mathrm{N}_{2}$ stream, and re-dissolved in $2 \mathrm{~mL}$ of acetonitrile. The solution was filtered through a $0.45 \mu \mathrm{m}$ syringe filter membrane prior to analysis by high performance liquid chromatography (HPLC).

The analysis of pyrene concentrations was conducted on a Shimadzu Class-VP HPLC system (Shimadzu, Japan) with a fluorescence detector (RF-10AXL). The separation of pyrene was achieved using a C18 reversed phase column (VP-ODS $150 \times 4.6 \mathrm{~mm} \mathrm{I}$. D., particle size $5 \mu \mathrm{m}$ ) using acetonitrile-water $(4: 1, \mathrm{v} / \mathrm{v})$ as the mobile phase at a flow rate of $2 \mathrm{~mL} \cdot \mathrm{min}^{-1}$. The excitation and emission wavelengths for pyrene were 296 and $404 \mathrm{~nm}$, respectively.

\section{DNA EXTRACTION}

DNA was extracted from $0.5 \mathrm{~g}$ of soil collected before contamination with pyrene and the soil samples collected on day 42 using the FastDNA ${ }^{\mathrm{TM}}$ spin kit for soil (MP Biomedicals LLC, OH, USA) following the manufacturer's instructions. Briefly, cell lysis was achieved by vigorous shaking in a FastPrep ${ }^{\circledR}$ bead-beating instrument at a speed of $6 \mathrm{~m} \cdot \mathrm{s}^{-1}$ for $40 \mathrm{~s}$. The homogenized mixture was centrifuged to separate the pellet containing soil and cell debris from the DNA in the supernatant. The DNA in the supernatant was further purified and dissolved in $100 \mu \mathrm{L}$ of elution buffer. DNA quality was assessed by electrophoresis on a $0.8 \%$ agarose gel. DNA quantity and purity were examined with a Nanodrop ${ }^{\circledR}$ ND-1000 UV-Vis Spectrophotometer (NanoDrop Technologies, Wilmington, DE, USA). The soil DNA was stored at $-20^{\circ} \mathrm{C}$ until use.

\section{REAL-TIME PCR}

To determine how pyrene influences the total bacterial biomass, the real-time PCR method was used to quantify the bacterial 16S rRNA gene with a CFX96 Optical Real-Time Detection System (Bio-Rad Laboratories, Inc., Hercules, CA, USA). The assay used forward primer 515F (5'-GTGCCAGCMGCCGCGG-3') and reverse primer 907R (5'-CCGTCAATTCMTTTRAGTTT- $\left.3^{\prime}\right)$ to target the V4 region of the bacterial $16 \mathrm{~S}$ rRNA gene. The realtime PCR standard curve for the bacterial $16 \mathrm{~S}$ rRNA gene was generated via gradient dilution of plasmid DNA. Real-time PCR was performed in a $20 \mu \mathrm{L}$ reaction mixture containing $10 \mu \mathrm{L}$ SYBR $^{\circledR}$ Premix Ex Taq $^{\mathrm{TM}}$ (TaKaRa Biotech, Dalian, China), $0.5 \mu \mathrm{mol} \cdot \mathrm{L}^{-1}$ of each primer, and $1 \mu \mathrm{L}$ template DNA ranging from 1 to $10 \mathrm{ng}$. Amplification of the 16S rRNA gene was initiated by denaturing at $95^{\circ} \mathrm{C}$ for $30 \mathrm{~s}$, followed by 40 cycles of $30 \mathrm{~s}$ at $95^{\circ} \mathrm{C}, 30 \mathrm{~s}$ at $55^{\circ} \mathrm{C}, 30 \mathrm{~s}$ at $72^{\circ} \mathrm{C}$, and $30 \mathrm{~s}$ with a plate read. A negative control using water as a template instead of DNA was always included. Real-time PCR was performed with three technical replications for each soil DNA sample. The amplification efficiency was $106 \%$ with an $R^{2}$ value of 0.994 .

To quantify the abundance of key pyrene catabolic gene pyrene dioxygenase gene nidA that encodes the large $(\alpha)$ terminal dioxygenase subunit and is responsible for initial aromatic ring dihydroxylation, real-time PCR was performed in a similar manner to that used to assess 16S rRNA gene quantity with changes in the primer sequences and amplification procedure. The forward primer sequence $5^{\prime}$-TTCCCGAGTACGAGGGATAC and reverse primer sequence $5^{\prime}$-TCACGTTGATGAACGACAAA were used to target a conserved $141 \mathrm{bp}$ region of the nidA gene (DeBruyn et al., 2007). Amplification of the nidA gene was performed using the following protocol (DeBruyn et al., 2007): $95^{\circ} \mathrm{C}$ for $30 \mathrm{~s} ; 40$ cycles of $94^{\circ} \mathrm{C}$ for $15 \mathrm{~s}, 56^{\circ} \mathrm{C}$ for $30 \mathrm{~s}$, $72^{\circ} \mathrm{C}$ for $30 \mathrm{~s}$, and $30 \mathrm{~s}$ with a plate read. The amplification efficiency was $95.3 \%$ with an $R^{2}$ value of 0.999 for the nidA gene.

\section{ILLUMINA SEOUENCING AND DATA ANALYSIS}

Pyrosequencing was performed on an Illumina Miseq platform by analyzing the V4 region (515F-907R) of the bacterial $16 \mathrm{~S}$ rRNA gene. The primer 515F (5'-GTGCCAGCMGCCGCGG$3^{\prime}$ ) was fused with a 12-bp barcode (Table S1) to resolve different samples. The sequence of reverse primer 907R was $5^{\prime}$-CCGTCAATTCMTTTRAGTTT- 3 '. Each $50 \mu \mathrm{L}$ of the PCR reaction mixture contained $1 \times$ PCR buffer $\left(\mathrm{Mg}^{2+}\right.$ plus), $0.2 \mathrm{mM}$ of each deoxynucleoside triphosphate, $0.4 \mathrm{mM}$ of each primer, $1.25 \mathrm{U}$ of TaKaRa Taq HS polymerase (TaKaRa Biotech, Dalian, China), and $1 \mu \mathrm{L}$ of soil DNA. The PCR reaction was performed in a thermal cycler (Bio-Rad Laboratories, Hercules, CA, USA) using the following cycling conditions: $94^{\circ} \mathrm{C}$ for $5 \mathrm{~min}$, followed by 32 cycles of $94^{\circ} \mathrm{C}$ for $30 \mathrm{~s}, 55^{\circ} \mathrm{C}$ for $30 \mathrm{~s}$, and $72^{\circ} \mathrm{C}$ for $45 \mathrm{~s}$, with a final extension of $72^{\circ} \mathrm{C}$ for $5 \mathrm{~min}$. The PCR product was visualized on a $1.8 \%$ agarose gel. The PCR amplicon band was excised from the gel and purified with an agarose gel DNA purification kit (TaKaRa Biotech, Dalian, China). The concentrations of the purified PCR amplicons were determined with a Nanodrop ${ }^{\circledR}$ ND-1000 UV-Vis Spectrophotometer (NanoDrop Technologies, Wilmington, DE, USA); the amplicons were then pooled in equimolar concentrations into a single tube in preparation for paired-end sequencing $(2 \times 250 \mathrm{bp})$ using the Illumina MiSeq platform at the Chengdu Institute of Biology, Chinese Academy of Sciences.

The Illumina sequence reads were processed using the quantitative insights into microbial ecology (QIIME) pipeline ${ }^{1}$. Briefly, low quality sequence reads (reads with lengths $<150 \mathrm{bp}$, ambiguous bases $>0$, homopolymers $>6$, primer mismatches, and average quality scores $<25)$ were removed and the 12 bp barcode was examined to assign the multiplexed reads to samples. Then, the Uchime algorithm was used to detect

${ }^{1} \mathrm{http}: / /$ qiime.org/tutorials/tutorial.html 
chimeric sequences with a chimera-free reference database (Edgar et al., 2011) via the Usearch tool. All chimeras were removed before further analysis. The clustering method was used to assign similar sequences to operational taxonomic units (OTUs) at a 97\% sequence similarity level (Edgar, 2010). A representative sequence from each OTU was aligned with PyNAST (Caporaso etal., 2010). The taxonomic classification of OTUs was processed using the RDP Classifier (Wang et al., 2007). The original sequence data have been deposited in the European Nucleotide Archive under accession number PRJEB7639.

To standardize sampling efforts and bring the pyrosequence data from different samples onto a common scale, sequences were subsampled to the same sequence depth $(10,000$ sequences per sample) using the Perl script daisychopper.pl (Gilbert et al., 2009; Wegner et al., 2013; Li et al., 2014). The relative abundance of each group at different taxonomic levels (phylum, class, order, family, and genus) was then summarized. Principal coordinate analysis ( $\mathrm{PCoA}$ ) of the pyrosequencing data was performed using the subsampled data to determine differences in microbial community structures using weighted UniFrac distances, a measurement that accounts for the phylogenetic relationship between different sequences and thus provides far more power than the taxon-based method (Lozupone and Knight, 2005; Hamady et al., 2010). Samples were clustered based on betweensamples weighted UniFrac distances using unweighted pair group method with arithmetic mean (UPGMA), and jackknifing was performed by resampling 100 times without replacement at a depth of 10,000 sequences per sample. Three different complementary non-parametric analyses for multivariate data (Zhou etal., 2012) including the analysis of similarities (ANOSIM; Clarke, 1993), non-parametric multivariate analysis of variance using distance matrices (adonis; Anderson, 2001), and a multiresponse permutation procedure (MRPP; Mielke and Berry, 2001; McCune and Grace, 2002) were used to investigate community structure differences between treatments. These methods were selected because traditional multivariate statistical analyses are too stringent in their assumptions (Anderson, 2001), and traditionally, it has been difficult for all datasets to meet the assumptions (e.g., normality, equal variances, and independence) of parametric statistics (Zhou et al., 2012). Weighted UniFrac distances were used for the ANOSIM, adonis, and MRPP analyses, and a Monte Carlo permutation was exploited to test the significance of the statistics. ANOSIM, adonis, and MRPP were processed with the "vegan" package in R software version 2.15.0.

\section{RESULTS}

\section{PYRENE DYNAMICS IN SOIL}

Soil microcosms were constructed with artificial pyrene contamination at three concentrations $\left(5,30\right.$, and $70 \mathrm{mg} \cdot \mathrm{kg}^{-1}$ d.w.s $)$ to study the biodegradation potential of red soil. The ability to degrade pyrene was investigated by detecting the concentration of pyrene on days $0,4,7,14,21,28$, and 42 during the incubation period (Figure 1). Intriguingly, no evident pyrene degradation was observed during the entire incubation period for all spiked pyrene concentrations.

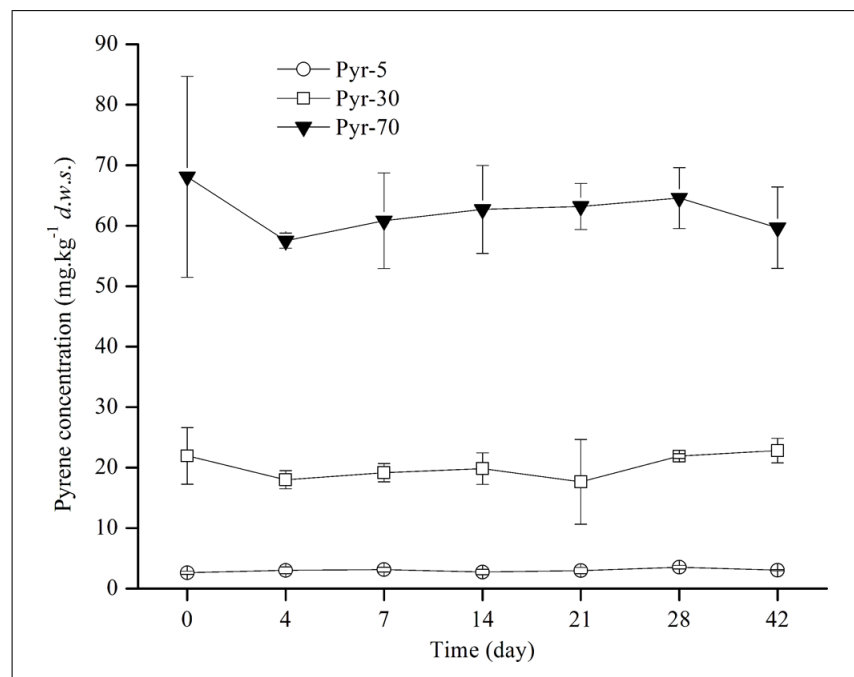

FIGURE 1 | Pyrene concentration dynamics in soil during the incubation period. The designations Pyr-5, Pyr-30, and Pyr-70 indicate that the soil was treated with different concentrations of pyrene representing 5 , 30 , and $70 \mathrm{mg} \cdot \mathrm{kg}^{-1}$ d.w.s., respectively. The designation d.w.s. refers to dry weight soil. The error bars represent the standard deviation of the means of triplicate microcosms.

\section{EFFECT OF PYRENE ON THE ABUNDANCE OF THE 16S rRNA and nidA GENES}

To understand the reasons that may lead to the observed slight degradation and the relationship between the abundance of pyrene-degrading bacteria and pyrene degradation, the abundance of a key pyrene-degradative gene (pyrene dioxygenase gene: nidA) was examined with the real-time PCR method. Additionally, the $16 \mathrm{~S}$ rRNA gene and the soil DNA content were quantified as a proxy for bacterial biomass. After 42 days of incubation, the abundance of the 16S rRNA gene copy number (biomass) in the control soil was unchanged, $5.56 \times 10^{9}$ copies per gram dry weight soil, compared with the original soil, $5.33 \times 10^{9}$ (Figure 2A). The persistence of pyrene to degradation at all spiking concentrations led to a non-significant $(P>0.05)$ decrease in $16 \mathrm{~S}$ rRNA gene copy number (biomass; Figure 2A). A similar pattern was observed for DNA content (Figure S1). Additionally, after 42 days of incubation, the quantity of the ndiA gene in the soils spiked with the tested low concentration of pyrene $\left(5 \mathrm{mg} \cdot \mathrm{kg}^{-1}\right.$ d.w.s. $)$ was not significantly affected compared with that of the control soil (Figure 2B). Interestingly, when the pyrene spiking concentration was increased to $30 \mathrm{mg} \cdot \mathrm{kg}^{-1}$ d.w.s., the quantity of the nidA gene was significantly decreased $(P<0.05)$ compared with the control (Figure 2B). When the pyrene spiking concentration increased to $70 \mathrm{mg} \cdot \mathrm{kg}^{-1}$ d.w.s., a further significant decrease in nidA gene copy number was observed (Figure 2B).

\section{EFFECT OF PYRENE ON BACTERIAL RICHNESS AND DIVERSITY}

The Illumina sequencing data were used to evaluate the effect of the presence of pyrene on bacterial richness and diversity. Based on the Illumina data, a total of 425,672 high quality sequences (Table S2) across all 15 samples or an average of 28,378 sequences for each sample were obtained after applying all quality filters. A total of $91.4 \%$ of the sequences were taxonomically classified 


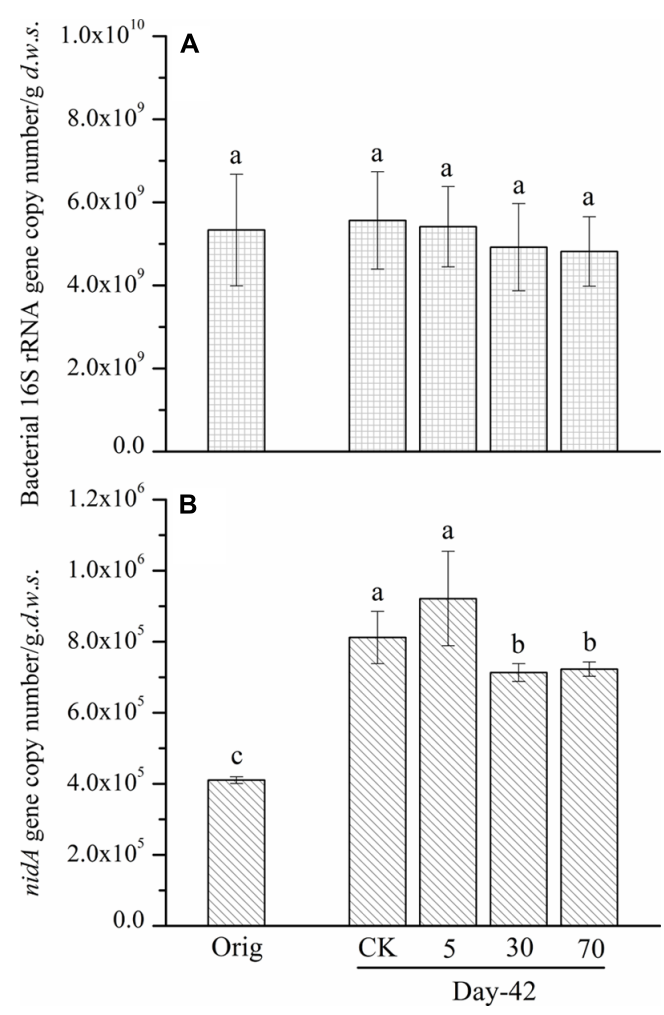

FIGURE 2 | Bacterial 16S rRNA gene (A) and nidA gene (B) copy number determined by real-time PCR from soil microcosms. The designation Orig denotes the original soil that did not receive any treatment. The designation control denotes the control soil that was treated with acetone. The designations 5, 30, and 70 refer to the soils that were treated with acetone-dissolved pyrene at concentrations of 5, 30, and $70 \mathrm{mg} \cdot \mathrm{kg}^{-1}$ d.w.s. Same letters indicate no significant differences by Duncan's multiple range test $(P<0.05)$. The error bars represent the SD of the means of triplicate microcosms.

as bacteria, and only $0.41 \%$ of the sequences were identified as archaea (Table S2).The observed OTUs (Figure S2A) and Shannon indices (Figure S2B) were used to determine whether the presence of pyrene resulted in adverse effects on bacterial richness and diversity. Pyrene addition resulted in a slight significant decrease in the number of OTUs and the Shannon index compared with the control treatment after 42 days of incubation. The higher the concentration of the spiked pyrene, the lower the bacterial richness and the diversity became.

\section{EFFECT OF PYRENE ON THE BACTERIAL COMMUNITY STRUCTURE}

The bacterial community structure is an overall reflection of the composition and abundance of different bacterial phylotypes within a microbial community. Therefore, changes in community structure were analyzed using the PCoA and UPGMA methods to evaluate specific effects of pyrene addition on the bacterial community from the viewpoint of microbial ecology. The day 42 samples from the control (CK) group clustered with the original soil samples in the PCoA data space (Figure 3A) and the UPGMA tree (Figure 3B), suggesting similar microbial community structures in the pyrene un-amended soil during the incubation period. Intriguingly, after 42 days of incubation, the pyrene-spiked samples formed a distinct cluster distant from the original soil samples and pyrene un-amended soil samples collected on day 42. Three non-parametric multivariate statistical tests (ANOSIM, adonis, and MRPP) also showed significant differences $(P<0.05)$ between the pyrenespiked samples and the control samples collected on day 42 (Table 1). Additionally, within the pyrene-spiked soils the samples were generally further separated (Figure 3A) and clustered (Figure 3B) by pyrene dosage; this result indicated that the pyrene levels in soil resulted in difference in microbial community structures.

\section{EFFECT OF PYRENE ON SPECIFIC BACTERIAL POPULATIONS AT THE HIGH TAXONOMIC LEVEL}

To identify specific bacterial populations that may be affected by pyrene, the relative abundance of the phylotypes were summarized at the phylum or lower taxonomic levels. The shift in relative abundance of the main phyla/classes (relative abundance $>0.1 \%$ were included) under different treatments is shown in Figure 4A. Although the relative abundance of the main phyla varied greatly under different treatments, 12 phyla/classes including Acidobacteria (23.6-31.4\%), Chloroflexi (12.4-21.8\%), Alphaproteobacteria (6.36-8.21\%), Betaproteobacteria (3.60$14.8 \%)$, Gammaproteobacteria (3.42-7.70\%), Deltaproteobacteria (2.30-2.97\%), Actinobacteria (5.44-7.22\%), AD3 (1.747.95\%), Planctomycetes (3.09-4.60\%), GAL15 (1.00-2.20\%), Bacteroidetes (1.00-1.26\%), and WPS-2 (1.00-2.28\%) were always abundant (relative abundance $>1.0 \%$ in all treatments) and shared bacterial groups (Figure 4A), accounting for a total of $86.0-87.5 \%$ of the whole community. Rare phyla (relative abundance $<1.0 \%$ in at least one treatment and $>0.1 \%$ in all treatments) comprised 10 phyla (Figure 4B) including Nitrospirae, Firmicutes, Armatimonadetes, Gemmatimonadetes, Crenarchaeota, Cyanobacteria, Chlorobi, Verrucomicrobia, Elusimicrobia, and WS3, accounting for a total of $4.09-5.45 \%$ of the whole community.

As total bacterial biomass was not significantly influenced by pyrene (Figure 2A; Figure S1), changes in relative abundance could then reflect the absolute abundance of specific phylotypes. It is expected that the persistence of pyrene to degradation may exert a toxic influence on some bacterial populations because the bacterial richness (Figure S2A) and diversity (Figure S2B) were decreased by pyrene. Indeed, seven out of the 12 abundant phyla/classes were significantly $(P<0.05)$ decreased in relative abundance with at least one concentration of pyrene after 42 days of incubation (Figures 5A-C). Specifically, Chloroflexi, AD3, WPS-2, and GAL15 were significantly decreased by all the tested pyrene dosages, including 5,30 , and $70 \mathrm{mg} \cdot \mathrm{kg}^{-1}$, Actinobacteria was significantly reduced at concentrations of 5 and $30 \mathrm{mg} \cdot \mathrm{kg}^{-1}$, and the Alphaproteobacteria and Deltaproteobacteria were significantly decreased at 5 and $30 \mathrm{mg} \cdot \mathrm{kg}^{-1}$, respectively. Additionally, the phylum Crenarchaeota (belong to Archaea) within the rare group was also significantly decreased $(P<0.05)$ by pyrene at a concentration of $30 \mathrm{mg} \cdot \mathrm{kg}^{-1}$ (Figure 5E). However, we did not observe a significant effect of pyrene on the relative abundance of the abundant groups Planctomycetes 


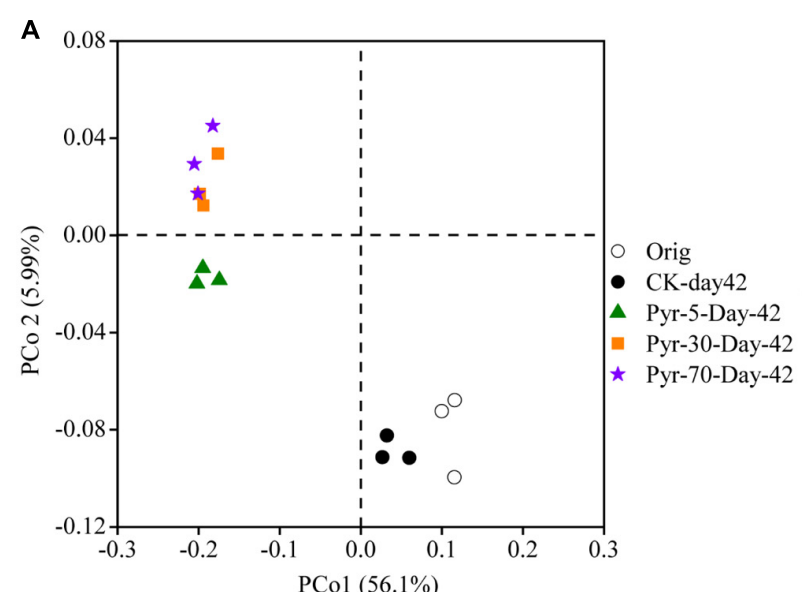

FIGURE 3 | Principal coordinate analysis (PCoA) (A) and unweighted pair group method with arithmetic mean cluster analysis (B) of microbial communities based on weighted UniFrac distances at a depth of 10,000 randomly sampled sequences per sample. The percentages in parentheses indicate the proportions of

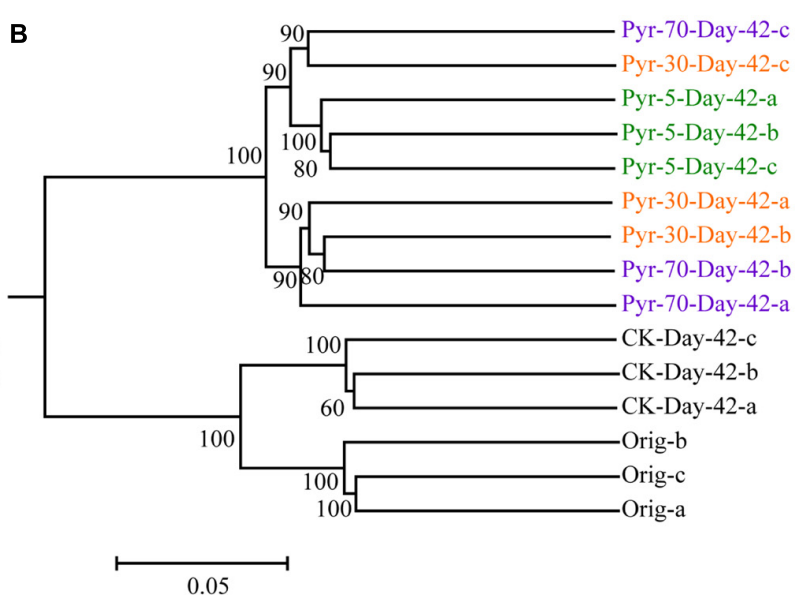

variation explained by each ordination axis. The numbers on the nodes indicate bootstrapping values for each node. The symbols "a", "b", and "c" near "Day-42" or "Orig" indicate triplicate microcosms for each treatment. All other designations are the same as those in Figure 2.

Table 1 | Significance tests using three statistical approaches to assess the effects of pyrene on overall microbial community structure on day 42.

\begin{tabular}{|c|c|c|c|c|c|c|}
\hline \multirow[t]{2}{*}{ Compared groups } & \multicolumn{2}{|c|}{ adonis $^{a}$} & \multicolumn{2}{|c|}{ ANOSIM $^{b}$} & \multicolumn{2}{|c|}{ MRPPc $^{c}$} \\
\hline & $\boldsymbol{F}$ & $P^{d}$ & $\boldsymbol{R}$ & $P^{d}$ & $\delta$ & $P^{d}$ \\
\hline CK-Day-42 vs. Pyr-30-Day-42 & 23.026 & 0.036 & 1 & 0.036 & 0.249 & 0.035 \\
\hline CK-Day-42 vs. Pyr-70-Day-42 & 27.249 & 0.038 & 1 & 0.042 & 0.248 & 0.045 \\
\hline
\end{tabular}

All tests (adonis, ANOSIM, and MRPP) are non-parametric multivariate analyses based on dissimilarities among samples.

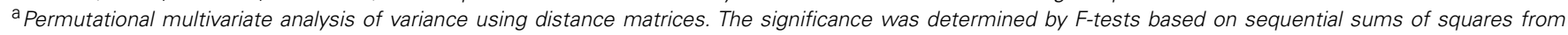
permutations of the raw data.

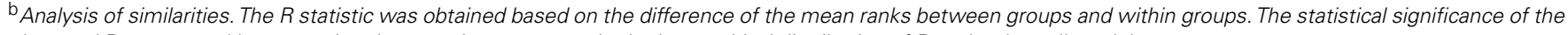
observed $R$ was tested by permuting the grouping vector to obtain the empirical distribution of $R$ under the null-model.

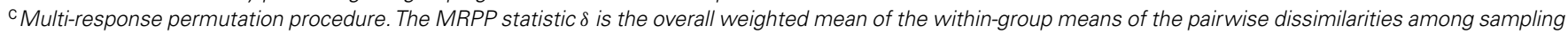
units. The significance tests indicate the fraction of permuted $\delta$ that is less than the observed $\delta$.

$\mathrm{d}$ The Bonferroni correction for the $P$ value of the significance test was used.

All other designations are the same as those in Figure 2.

and Bacteroidetes (Figures $\mathbf{5 A - C}$ ) and the nine other rare phylotypes including Firmicutes, Nitrospirae, Armatimonadetes, Cyanobacteria, Gemmatimonadetes, Chlorobi, Verrucomicrobia, Elusimicrobia, and WS3 (Figures 5D-F). Intriguingly, some phylotypes including Acidobacteria, Betaproteobacteria, and Gammaproteobacteria were enriched, as revealed by the significant increase in relative abundance at different concentrations of pyrene (Figures 5A-C) although significant pyrene degradation was not observed at any pyrene concentration (Figure 1). These results indicate that the persistence of pyrene to degradation affected the abundance of specific populations at a higher taxonomic level (phyla/classes level).

\section{EFFECT OF PYRENE ON SPECIFIC BACTERIAL POPULATIONS AT THE LOWER TAXONOMIC LEVEL}

More than $88.9 \%$ of the sequences could be taxonomically classified at the taxonomic level of order or higher, but only 62.6 and $17.7 \%$ of the sequences could be classified at the family and genus levels, respectively (Table S2). The relative abundance of each phylotype was then further analyzed at the order level to understand which bacterial populations were affected by pyrene on a finer taxonomic level. Among the main orders (with relative abundance $>0.1 \%$ ), those phylotypes that were significantly affected by pyrene in terms of relative abundance and could be taxonomically classified at the order level are shown in Figure 6. Twelve orders (Figure 6A) covering the phyla Acidobacteria, Actinobacteria, Chloroflexi, Planctomycetes, Alphaproteobacteria, Deltaproteobacteria, and Crenarchaeota were significantly reduced $(P<0.05)$ in relative abundance following incubation with at least one concentration of pyrene. Intriguingly, nine orders were found to be increased in relative abundance (Figure 6B) although no significant pyrene degradation was observed. These results further revealed that pyrene affected specific microbial populations at a lower taxonomic rank (order level). 

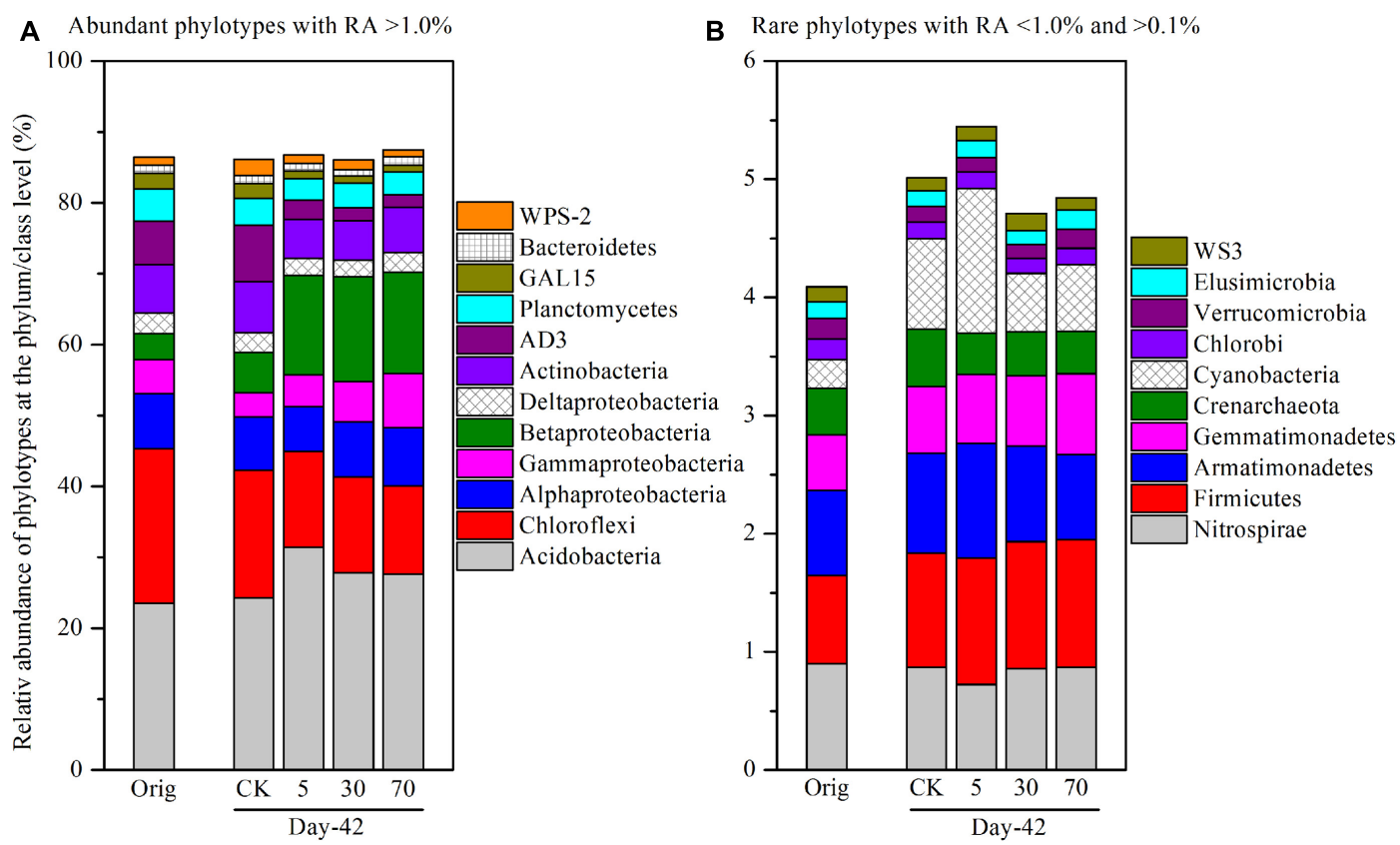

FIGURE 4 | Relative abundance of abundant phylotypes (A) and rare phylotypes (B) at the phylum or class (only for Proteobacteria) level. Abundant phylotypes refer to those microbial groups with relative abundance $(\mathrm{RA})>1.0 \%$ under all treatments. Rare phylotypes refer to those microbial group with $\mathrm{RA}<1.0 \%$ under at least one treatment and $>0.1 \%$ under all other treatments. The statistical analysis results are the same as those in Figure 6. All other designations are the same as those in Figure 2.

\section{DISCUSSION}

We did not observe evidence of pyrene degradation in the tested red soil. To some extent, the following reasons may explain this phenomenon.

According to our Miseq sequencing data, some previously reported pyrene-degradative phylotypes were detected in the soil, but their relative abundance were reduced or remained stable in the presence of pyrene. The genus Mycobacterium is a widely distributed (DeBruyn et al., 2009) and well characterized (Stingley et al., 2004; Kim et al., 2008; DeBruyn et al., 2011) pyrene-degradative population. A few studies have found that the abundance of fast-growing Mycobacterium was positively associated with pyrene degradation (DeBruyn et al., 2007; Peng et al., 2010). Interestingly, our study revealed that the relative abundance of Mycobacterium following the pyrene-spiking treatment was significantly decreased $(P<0.05)$ compared with the control treatment (Figure S3A) after 42 days of incubation. Four other bacterial phylotypes found to be able to degrade pyrene in a small number of studies including Bacillus (Ling et al., 2011), Rhodococcus (Walter et al., 1991), Pseudoxanthomonas (Klankeo et al., 2009), and Microbacterium (Wongwongsee et al., 2013) were also detected in our study. However, their relative abundance remained stable following exposure to pyrene after a 42-day incubation period (Figures S3B-E). These results revealed toxic effect of pyrene on some functional groups.

A degradative population is usually considered to possess key degradative genes such as the PAH dioxygenase gene (DeBruyn et al., 2007, 2009). Some studies have reported positive relationships between PAH biodegradation/contamination and the abundance of PAH-dioxygenase genes (Dionisi et al., 2004; Tuomi et al., 2004). Peng etal. (2010) found that the copy number of pyrene dioxygenase gene (nidA gene) increased to approximate 500 -fold in a pyrene polluted soil and the dissipation of pyrene was up to $80 \%$ after 2 months of incubation. Therefore, the abundance of nidA gene was considered to serve as the biomarker for pyrene degradation (DeBruyn et al., 2007; Peng et al., 2010). In our study, real-time PCR data showed stability with regard to $16 \mathrm{~S}$ rRNA gene copy number after pyrene exposure; microbial DNA content was also unaffected by pyrene. However, a significant decrease (at 30 and $70 \mathrm{mg} \cdot \mathrm{kg}^{-1}$ d.w.s of pyrene) in the pyrene dioxygenase gene (nidA) was observed. These results demonstrate that existence of pyrene exerted a deleterious influence on specific bacterial populations such as pyrene-degrading phylotypes. On the other hand, the significant decrease or stability of the abundance of nidA gene also demonstrates that Gram-positive bacteria were not able to degrade pyrene in the tested soil since nidA is usually found in Gram-positive bacteria like Actinobacteria (Khan et al., 2001; Brezna et al., 2003; Cébron et al., 2008; DeBruyn et al., 2009). This was supported by our results which showed that the relative abundance of Actinobacteria was reduced. It should be noted that the primers used for amplify the nidA gene were designed according to determination of the conserved regions of nidA from several pyrene-degrading Mycobacterium (DeBruyn et al., 2007). Designing a more universal primer targeting pyrene dioxygenase genes from more pyrene-degrading bacterial populations rather than just from Mycobacterium may be helpful for further study.

Furthermore, some putative pyrene degrading bacteria may not be at work in pyrene degradation in the tested soil. The exposure 


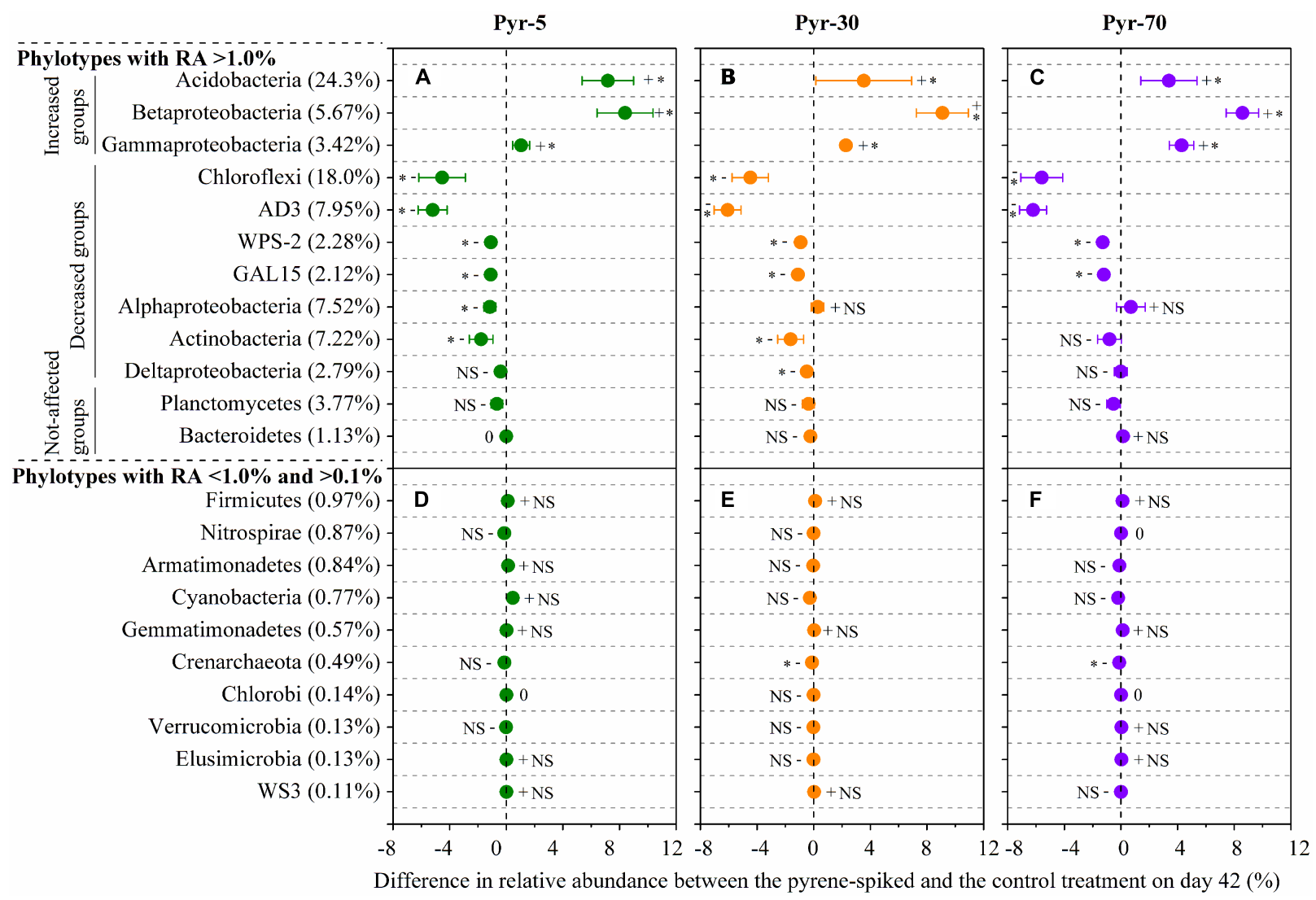

FIGURE 5 | Differences in relative abundance between the pyrene-spiked and control microcosms on day $\mathbf{4 2}$ for the abundant (relative abundance $>1.0 \%$ in all treatments) $(\mathrm{A}-\mathrm{C})$ and rare (relative abundance $<1.0 \%$ in at least one treatment and $>0.1 \%$ in all treatments) (D-F) phylotypes at the phylum or class (only for Proteobacteria) level. The net difference in relative abundance was calculated as the relative abundance under pyrene-spiked treatment - the relative abundance of the phylotype under control treatment. The error bars represent the standard error of the means. As for the abundant phylotypes, groups increased in relative abundance (Increased groups) are shown first, followed by phylotypes that are decreased
(Decreased groups) in relative abundance and phylotypes that are not significantly affected by pyrene (Not-affected groups). For the rare phylotypes, the microbial populations are presented in descending order on the basis of their relative abundance in the control treatment because only one population was significantly affected by pyrene. The percent value in the parentheses refers to the relative abundance in the control treatment. The symbols " +", "-," and " 0 " indicate that the relative abundance was increased, decreased, or stable compared with the control. The symbol "*" denotes significant differences at $P<0.05$; NS denotes no significant difference $(P>0.05)$. All other designations are the same as those in Figure 2. time to pyrene could be considered as one of limited factors. The growth, multiplication, and adaptation of the pyrene-degradative populations may be a time-consuming process and the 42 days of exposure to pyrene may not be long enough to lead to the formation of the pyrene-degradative consortium. Johnsen and Karlson (2005) found that pyrene could be mineralized in soils collected from industrialized areas rather than in pristine forest soils within a 140-day test period. Additionally, it is also possible that the dosage of pyrene is not high enough since different microbes have catabolic enzymes that are activated at different levels of pollution. A previous study has shown that only when the concentration of naphthalene was higher than $30 \mu \mathrm{M}$ could the Pseudomonas isolates actively degrade naphthalene (Huang et al., 2009). Furthermore, some other environmental factors, such as the molar ratio of carbon, nitrogen, and phosphate (C/N/P), the nitrogen form, pH, etc., may limit the PAH degradation (Roling et al., 2002; Simarro et al., 2011). Simarro et al. (2011) have optimized the six key abiotic factors in the process of PAH (naphthalene, phenanthrene, and anthracene) biodegradation by a bacterial consortium and revealed that high concentrations of nutrients $(\mathrm{C} / \mathrm{N} / \mathrm{P}$ molar ratio of 100:21:16; a mixture of glucose and PAHs as carbon source) and soluble forms of nitrogen and iron $\left(\mathrm{NaNO}_{3}\right.$ as nitrogen source; $\mathrm{Fe}_{2}\left(\mathrm{SO}_{4}\right)_{3}$ as iron source using a concentration of $\left.0.1 \mathrm{~mol} \cdot \mathrm{L}^{-1}\right)$ at neutral $\mathrm{pH}(7.0)$ favored the biodegradation. Therefore, further multifactorial experiment is necessary to determine the constraint abiotic factors leading to the non-degradation of pyrene in the red soil.

Pyrene addition slightly lowered the bacterial richness and diversity and altered the bacterial community structure. In total, within taxonomically classified phylotypes at the phylum or class (only for Proteobacteria) level, the relative abundance of seven abundant phyla/classes (relative abundance $>1.0 \%$ ) and one phylum with relatively low abundance (relative abundance $<1.0$ and $>0.1 \%$ ) were significantly reduced by pyrene treatment at a coarse taxonomic level. Additionally, 12 orders were decreased in relative abundance at a finer taxonomic level. A total of three phyla/classes 


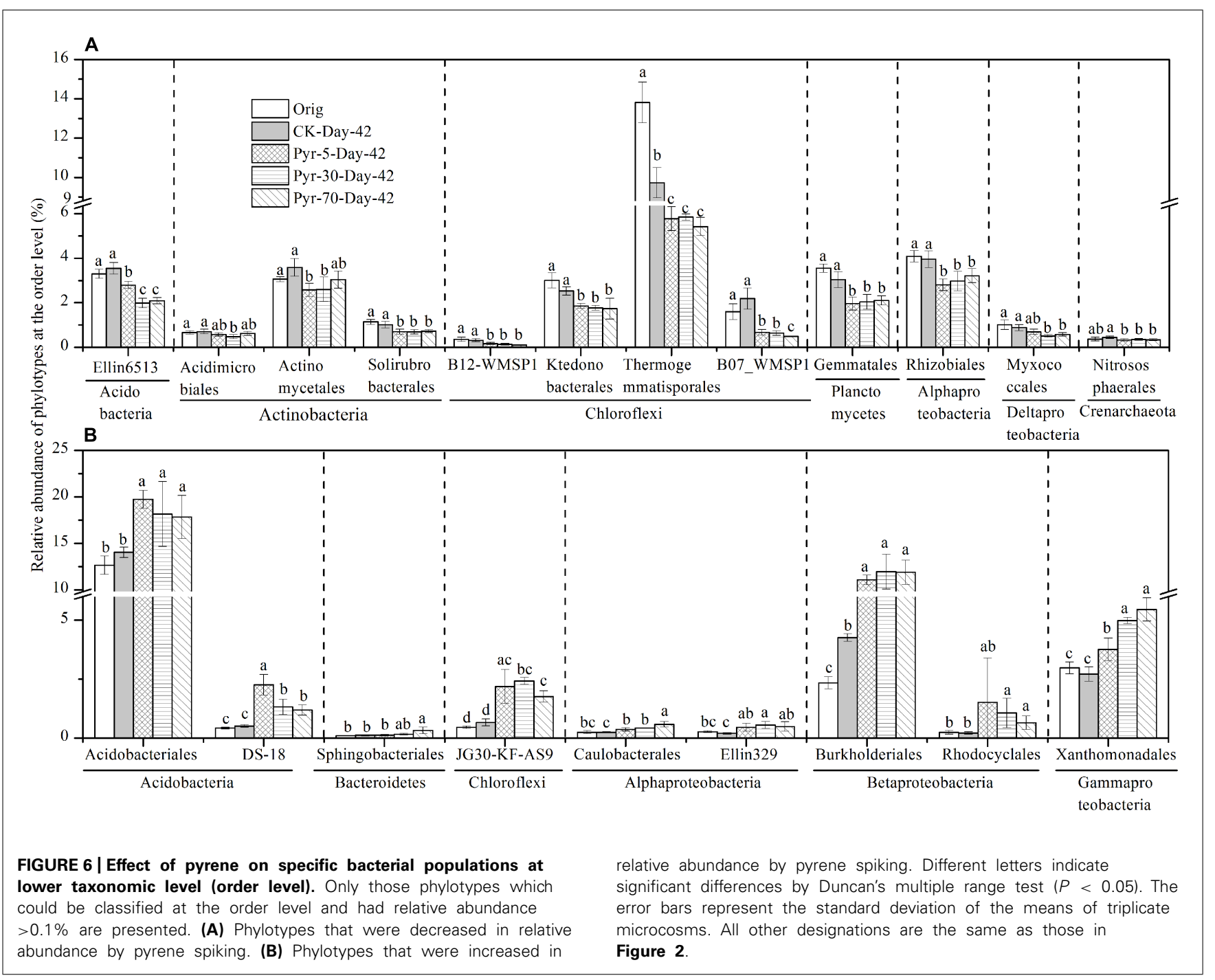

and nine orders were significantly increased in relative abundance (termed as increased phylotypes), possibly as a result of improved competitive ability. We speculate that there may be niche competition (Cunliffe and Kertesz, 2006) between the increased and decreased populations. The increased phylotypes might possess ecological advantages that allow them to survive, multiply, and compete in contaminated soils. It is also possible that the decreased phylotypes were more sensitive to pyrene, resulting in cell death due to pyrene toxicity. In this case, nutrients released from the cells of the decreased phylotypes after death could be utilized by the increased phylotypes for better growth. Further work should be performed to test this hypothesis.

Several populations were significantly decreased in relative abundance such as Actinobacteria (including three orders, Acidimicrobiales, Actinomycetales, and Solirubrobacterales). The decrease of Actinobacteria is contrast with most studies which found that the phylum was enriched where PAH degradation was observed based on the 454 pyrosequencing method (Sun etal., 2014) or stable isotope probing technique (Peng etal., 2013). Lower relative abundance of Actinobacteria in high PAH pollution has very recently been reported (Mukherjee et al., 2014). Moreover, some microbial taxa were indeed enriched at the phylum, class, or order level. Four significantly enriched orders were observed, including Burkholderiales and Rhodocyclales in Betaproteobacteria, Xanthomonadales in Gammaproteobacteria, and Sphingobacteriales in Bacteroidetes. These groups have been found in other soils or sediments contaminated by petroleum hydrocarbon, PAHs, and other hydrocarbons (Gomes et al., 2010; Greer, 2010; Mao et al., 2012; Castro-Silva et al., 2013), but in our case were not able to degrade the added pyrene.

In summary, the biodegradation of pyrene was not observed when the tested clean soil (not a PAH historically contaminated soil) was spiked with pyrene. The poor degradation ability was associated with the stability or significant decrease of the abundance of the pyrene dioxygenase gene (nidA). Even though some well-known pyrene-degrading populations such as Mycobacteirum, Bacillus, Rhodococcus, Pseudoxanthomonas, and Microbacterium were detected in the soil according to the Miseq data, they were not at work in pyrene degradation based on the observation that their relative abundance was reduced or stable. 
Although not degraded, pyrene led to a slight decrease in bacterial richness after 42 days of incubation and altered the whole bacterial community structure. This work is helpful for the ecological evaluation of the effect of PAHs on soil ecosystems in terms of microbial ecology.

\section{ACKNOWLEDGMENTS}

This work was supported by the Jiangsu Postdoctoral Science Foundation, China (1302031B), the National Natural Science Foundation of China (41271329 and 41230858), and the National High Technology Research and Development Program (863) of China (2007AA061101). The authors would like to extend their gratitude to Ye Zhu, Shijiang Feng, and Yan Zhou for their assistance in sample collection. The authors thank Prof. Xiangzhen Li, Dr. Junpeng Rui, Dr. Jiaxing An, Dr. Minjie Yao, and Shiheng Zhang from Chengdu Institute of Biology, Chinese Academy of Sciences for their help in Illumina sequencing and bioinformatic analyses. The authors would also like to thank the anonymous reviewers for their comments and suggestions that helped us to greatly improve the manuscript.

\section{SUPPLEMENTARY MATERIAL}

The Supplementary Material for this article can be found online at: http://www.frontiersin.org/journal/10.3389/fmicb.2015.00022/ abstract

\section{REFERENCES}

Anderson, M. J. (2001). A new method for non-parametric multivariate analysis of variance. Austral Ecol. 26, 32-46. doi: 10.1111/j.1442-9993.2001.01070.pp.x

Brezna, B., Khan, A. A., and Cerniglia, C. E. (2003). Molecular characterization of dioxygenases from polycyclic aromatic hydrocarbon-degrading Mycobacterium spp. FEMS Microbiol. Lett. 223, 177-183. doi: 10.1016/S0378-1097(03)00328-8

Cébron, A., Norini, M. P., Beguiristain, T., and Leyval, C. (2008). Real-Time PCR quantification of PAH-ring hydroxylating dioxygenase (PAH-RHD $\alpha$ ) genes from Gram positive and Gram negative bacteria in soil and sediment samples. J. Microbiol. Methods 73, 148-159. doi: 10.1016/j.mimet.2008.01.009

Caporaso, J. G., Bittinger, K., Bushman, F. D., Desantis, T. Z., Andersen, G. L., and Knight, R. (2010). PyNAST: a flexible tool for aligning sequences to a template alignment. Bioinformatics 26, 266-267. doi: 10.1093/bioinformatics/btp636

Castro-Silva, C., Ruiz-Valdiviezo, V. M., Valenzuela-Encinas, C., AlcántaraHernandez, R. J., Navarro-Noya, Y. E., Vázquez-Núñez, E., et al. (2013). The bacterial community structure in an alkaline saline soil spiked with anthracene. Electron. J. Biotechn. 16:10. doi: 10.2225/vol16-issue5-fulltext-14

Clarke, K. R. (1993). Nonparametric multivariate analyses of changes in community structure. Aust. J. Ecol. 18, 117-143. doi: 10.1111/j.1442-9993.1993.tb00438.x

Cunliffe, M., and Kertesz, M. A. (2006). Effect of Sphingobium yanoikuyae B1 inoculation on bacterial community dynamics and polycyclic aromatic hydrocarbon degradation in aged and freshly PAH-contaminated soils. Environ. Pollut. 144, 228-237. doi: 10.1016/j.envpol.2005.12.026

DeBruyn, J. M., Chewning, C. S., and Sayler, G. S. (2007). Comparative quantitative prevalence of Mycobacteria and functionally abundant nidA, nahAc, and nagAc dioxygenase genes in coal tar contaminated sediments. Environ. Sci. Technol. 41, 5426-5432. doi: 10.1021/es070406c

DeBruyn, J. M., Mead, T. J., and Sayler, G. S. (2011). Horizontal transfer of PAH catabolism genes in Mycobacterium: evidence from comparative genomics and isolated pyrene-degrading bacteria. Environ. Sci. Technol. 46, 99-106. doi: $10.1021 /$ es201607y

DeBruyn, J. M., Mead, T. J., Wilhelm, S. W., and Sayler, G. S. (2009). PAH biodegradative genotypes in Lake Erie sediments: evidence for broad geographical distribution of pyrene-degrading mycobacteria. Environ. Sci. Technol. 43, 3467-3473. doi: 10.1021/es803348g

Dionisi, H. M., Chewning, C. S., Morgan, K. H., Menn, F. M., Easter, J. P., and Sayler, G. S. (2004). Abundance of dioxygenase genes similar to Ralstonia sp. strain U2 nagAc is correlated with naphthalene concentrations in coal tar-contaminated freshwater sediments. Appl. Environ. Microbiol. 70, 3988-3995. doi: 10.1128/aem.70.3.3988-3995.2004

Edgar, R. C. (2010). Search and clustering orders of magnitude faster than BLAST. Bioinformatics 26, 2460-2461. doi: 10.1093/bioinformatics/btq461

Edgar, R. C., Haas, B. J., Clemente, J. C., Quince, C., and Knight, R. (2011). UCHIME improves sensitivity and speed of chimera detection. Bioinformatics 27, 2194 2200. doi: 10.1093/bioinformatics/btr381

Gans, J., Wolinsky, M., and Dunbar, J. (2005). Computational improvements reveal great bacterial diversity and high metal toxicity in soil. Science 309, 1387-1390. doi: 10.1126/science. 1112665

Gilbert, J. A., Field, D., Swift, P., Newbold, L., Oliver, A., Smyth, T., et al. (2009). The seasonal structure of microbial communities in the Western English Channel. Environ. Microbiol. 11, 3132-3139. doi: 10.1111/j.1462-2920.2009.02017.x

Gomes, N. C. M., Flocco, C. G., Costa, R., Junca, H., Vilchez, R., Pieper, D. H., et al. (2010). Mangrove microniches determine the structural and functional diversity of enriched petroleum hydrocarbon-degrading consortia. FEMS Microbiol. Ecol. 74, 276-290. doi: 10.1111/j.1574-6941.2010.00962.x

Greer, C. W. (2010). "Bacterial diversity in hydrocarbon-polluted rivers, estuaries and sediments," in Handbook of Hydrocarbon and Lipid Microbiology, ed. K. N. Timmis (Berlin Heidelberg: Springer-Verlag), 2329-2338. doi: 10.1007/978-3540-77587-4_169

Hamady, M., Lozupone, C., and Knight, R. (2010). Fast UniFrac: facilitating high-throughput phylogenetic analyses of microbial communities including analysis of pyrosequencing and PhyloChip data. ISME J. 4, 17-27. doi: 10.1038/ismej.2009.97

Heitkamp, M. A., Franklin, W., and Cerniglia, C. E. (1988). Microbial metabolism of polycyclic aromatic hydrocarbons: isolation and characterization of a pyrenedegrading bacterium. Appl. Environ. Microbiol. 54, 2549-2555.

Hollister, E. B., Engledow, A. S., Hammett, A. J. M., Provin, T. L., Wilkinson, H. H., and Gentry, T. J. (2010). Shifts in microbial community structure along an ecological gradient of hypersaline soils and sediments. ISME J. 4, 829-838. doi: 10.1038/ismej.2010.3

Huang, G. Q., and Zhao, Q. G. (2014). Initial exploration of red soil ecology. Acta Ecologica Sinica 34, 5173-5181. doi: 10.5846/stxb201405100944

Huang, W. E., Ferguson, A., Singer, A. C., Lawson, K., Thompson, I. P., Kalin, R. M., et al. (2009). Resolving genetic functions within microbial populations: in situ analyses using rRNA and mRNA stable isotope probing coupled with single-cell Raman-fluorescence in situ hybridization. Appl. Environ. Microbiol. 75, 234-241. doi: 10.1128/aem.01861-08

Huse, S. M., Dethlefsen, L., Huber, J. A., Welch, D. M., Relman, D. A., and Sogin, M. L. (2008). Exploring microbial diversity and taxonomy using SSU rRNA hypervariable tag sequencing. PLoS Genet. 4:e1000255. doi: 10.1371/journal.pgen.1000255 Jin, H. M., Jeong, H., Moon, E. J., Math, R. K., Lee, K., Kim, H. J., et al. (2011). Complete genome sequence of the polycyclic aromatic hydrocarbondegrading bacterium Alteromonas sp. strain SN2. J. Bacteriol. 193, 4292-4293. doi: 10.1128/jb.05252-11

Johnsen, A. R., and Karlson, U. (2005). PAH degradation capacity of soil microbial communities - does it depend on PAH exposure? Microb. Ecol. 50, 488-495. doi: 10.1007/s00248-005-0022-5

Kawasaki, A., Watson, E. R., and Kertesz, M. A. (2012). Indirect effects of polycyclic aromatic hydrocarbon contamination on microbial communities in legume and grass rhizospheres. Plant Soil 358, 162-175. doi: 10.1007/s11104-011-1089-z

Khan, A. A., Wang, R. F., Cao, W. W., Doerge, D. R., Wennerstrom, D., and Cerniglia, C. E. (2001). Molecular cloning, nucleotide sequence, and expression of genes encoding a polycyclic aromatic ring dioxygenase from Mycobacterium sp. strain PYR-1. Appl. Environ. Microbiol. 67, 3577-3585. doi: 10.1128/aem.67.8.35773585.2001

Kim, S. J., Kweon, O., Jones, R. C., Edmondson, R. D., and Cerniglia, C. E. (2008). Genomic analysis of polycyclic aromatic hydrocarbon degradation in Mycobacterium vanbaalenii PYR-1. Biodegradation 19, 859-881. doi: 10.1007/s10532-008-9189-z

Klankeo, P., Nopcharoenkul, W., and Pinyakong, O. (2009). Two novel pyrenedegrading Diaphorobacter sp. and Pseudoxanthomonas sp. isolated from soil. J. Biosci. Bioeng. 108, 488-495. doi: 10.1016/j.jbiosc.2009.05.016

Li, X. Z., Rui, J. P., Mao, Y. J., Yannarell, A., and Mackie, R. (2014). Dynamics of the bacterial community structure in the rhizosphere of a maize cultivar. Soil Biol. Biochem. 68, 392-401. doi: 10.1016/j.soilbio.2013.10.017

Ling, J. Y., Zhang, G. Y., Sun, H. B., Fan, Y. Y., Ju, J. H., and Zhang, C. K. (2011). Isolation and characterization of a novel pyrene-degrading Bacillus vallismortis 
strain JY3A. Sci. Total Environ. 409, 1994-2000. doi: 10.1016/j.scitotenv.2011. 02.020

Lozupone, C., and Knight, R. (2005). UniFrac: a new phylogenetic method for comparing microbial communities. Appl. Environ. Microbiol. 71, 8228-8235. doi: 10.1128/aem.71.12.8228-8235.2005

Maliszewska-Kordybach, B. (1996). Polycyclic aromatic hydrocarbons in agricultural soils in Poland: preliminary proposals for criteria to evaluate the level of soil contamination. Appl. Geochem. 11, 121-127. doi: 10.1016/0883-2927(95)00076-3

Mao, J., Luo, Y. M., Teng, Y., and Li, Z. G. (2012). Bioremediation of polycyclic aromatic hydrocarbon-contaminated soil by a bacterial consortium and associated microbial community changes. Int. Biodeterior. Biodegrad. 70, 141-147. doi: 10.1016/j.ibiod.2012.03.002

Masakorala, K., Yao, J., Cai, M., Chandankere, R., Yuan, H., and Chen, H. (2013). Isolation and characterization of a novel phenanthrene (PHE) degrading strain Psuedomonas sp. USTB-RU from petroleum contaminated soil. J. Hazard. Mater. 263, 493-500. doi: 10.1016/j.jhazmat.2013.10.007

McCune, B., and Grace, J. B. (2002). Analysis of Ecological Communities. Gleneden Beach, OR: MjM Software Design.

Mielke, P. W., and Berry, K. J. (2001). Permutation Methods: A Distance Function Approach. New York: Springer. doi: 10.1007/978-1-4757-3449-2

Mukherjee, S., Heinonen, M., Dequvire, M., Sipilä, T., Pulkkinen, P., and Yrjälä, K. (2013). Secondary succession of bacterial communities and co-occurrence of phylotypes in oil-polluted Populus rhizosphere. Soil Biol. Biochem. 58, 188-197. doi: 10.1016/j.soilbio.2012.11.018

Mukherjee, S., Juottonen, H., Siivonen, P., Lloret Quesada, C., Tuomi, P., Pulkkinen, P., et al. (2014). Spatial patterns of microbial diversity and activity in an aged creosote-contaminated site. ISME J. 8, 2131-2142. doi: 10.1038/ismej.2014.151

Peng, J. J., Cai, C., Qiao, M., Li, H., and Zhu, Y. G. (2010). Dynamic changes in functional gene copy numbers and microbial communities during degradation of pyrene in soils. Environ. Pollut. 158, 2872-2879. doi: 10.1016/j.envpol.2010.06.020

Peng, J. J., Zhang, Y., Su, J. Q., Qiu, Q. F., Jia, Z. J., and Zhu, Y. G. (2013). Bacterial communities predominant in the degradation of ${ }^{13} \mathrm{C}_{4}$ 4,5,9,10-pyrene during composting. Bioresour. Technol. 143, 608-614. doi: 10.1016/j.biortech.2013.06.039

Ping, L. F., Zhang, C. R., Zhang, C. P., Zhu, Y. H., He, H. M., Wu, M., et al. (2014). Isolation and characterization of pyrene and benzo[a]pyrene-degrading Klebsiella pneumonia PL1 and its potential use in bioremediation. Appl. Microbiol. Biotechnol. 98, 3819-3828. doi: 10.1007/s00253-013-5469-6

Qian, W., Ni, J.Z., Luo, Y. M., Li, X. H., and Zou, D. X. (2007). Determination of polycyclic aromatic hydrocarbons in soil by high performance liquid chromatography with fluorescence detection. Chin. J. Chromatogr. 25, 221-225.

Roling, W. F. M., Milner, M. G., Jones, D. M., Lee, K., Daniel, F., Swannell, R. J. P., et al. (2002). Robust hydrocarbon degradation and dynamics of bacterial communities during nutrient-enhanced oil spill bioremediation. Appl. Environ. Microbiol. 68, 5537-5548. doi: 10.1128/aem.68.11.5537-5548.2002

Sauret, C., Severin, T., Vetion, G., Guigue, C., Goutx, M., Pujo-Pay, M., et al. (2014). 'Rare biosphere' bacteria as key phenanthrene degraders in coastal seawaters. Environ. Pollut. 194, 246-253. doi: 10.1016/j.envpol.2014.07.024

Simarro, R., Gonzalez, N., Bautista, L. F., Sanz, R., and Molina, M. C. (2011) Optimisation of key abiotic factors of PAH (naphthalene, phenanthrene, and anthracene) biodegradation process by a bacterial consortium. Water Air Soil Pollut. 217, 365-374. doi: 10.1007/s11270-010-0593-8

Singleton, D. R., Jones, M. D., Richardson, S. D., and Aitken, M. D. (2013). Pyrosequence analyses of bacterial communities during simulated in situ bioremediation of polycyclic aromatic hydrocarbon-contaminated soil. Appl. Microbiol. Biotechnol. 97, 8381-8391. doi: 10.1007/s00253-012-4531-0

Singleton, D. R., Powell, S. N., Sangaiah, R., Gold, A., Ball, L. M., and Aitken, M. D. (2005). Stable-isotope probing of bacteria capable of degrading salicylate, naphthalene, or phenanthrene in a bioreactor treating contaminated soil. Appl. Environ. Microbiol. 71, 1202-1209. doi: 10.1128/aem.71.3.1202-1209.2005

Singleton, D. R., Richardson, S. D., and Aitken, M. D. (2011). Pyrosequence analysis of bacterial communities in aerobic bioreactors treating polycyclic aromatic hydrocarbon-contaminated soil. Biodegradation 22, 1061-1073. doi: 10.1007/s10532-011-9463-3

Sipilä, T. P., Keskinen, A. K., Åkerman, M. L., Fortelius, C., Haahtela, K., and Yriälä, K. (2008). High aromatic ring-cleavage diversity in birch rhizosphere: $\mathrm{PAH}$ treatment-specific changes of I.E.3 group extradiol dioxygenases and 16S rRNA bacterial communities in soil. ISME J. 2, 968-981. doi: 10.1038/ismej.2008.50
Stingley, R. L., Khan, A. A., and Cerniglia, C. E. (2004). Molecular characterization of a phenanthrene degradation pathway in Mycobacterium vanbaalenii PYR-1. Biochem. Biophys. Res. Commun. 322, 133-146. doi: 10.1016/j.bbrc.2004.07.089

Sun, G. D., Xu, Y., Liu, Y., and Liu, Z. P. (2014). Microbial community dynamics of soil mesocosms using Orychophragmus violaceus combined with Rhodococcus ruber Em1 for bioremediation of highly PAH-contaminated soil. Appl. Microbiol. Biotechnol. 98, 10243-10253. doi: 10.1007/s00253-014-5971-5

Tervahauta, A. I., Fortelius, C., Tuomainen, M., Kerman, M. L., Rantalainen, K., Sipila, T., et al. (2009). Effect of birch (Betula spp.) and associated rhizoidal bacteria on the degradation of soil polyaromatic hydrocarbons, $\mathrm{PAH}$-induced changes in birch proteome and bacterial community. Environ. Pollut. 157, 341346. doi: 10.1016/j.envpol.2008.06.031

Tuomi, P. M., Salminen, J. M., and Jorgensen, K. S. (2004). The abundance of nahAc genes correlates with the ${ }^{14} \mathrm{C}$-naphthalene mineralization potential in petroleum hydrocarbon-contaminated oxic soil layers. FEMS Microbiol. Ecol. 51, 99-107. doi: 10.1016/j.femsec.2004.07.011

Uyttebroek, M., Breugelmans, P., Janssen, M., Wattiau, P., Joffe, B., Karlson, U., et al. (2006). Distribution of the Mycobacterium community and polycyclic aromatic hydrocarbons (PAHs) among different size fractions of a long-term PAH-contaminated soil. Environ. Microbiol. 8, 836-847. doi: 10.1111/j.14622920.2005.00970.x

Viñas, M., Sabaté, J., Espuny, M. J., and Solanas, A. M. (2005). Bacterial community dynamics and polycyclic aromatic hydrocarbon degradation during bioremediation of heavily creosote-contaminated soil. Appl. Environ. Microbiol. 71, 7008-7018. doi: 10.1128/aem.71.11.7008-7018.2005

Walter, U., Beyer, M., Klein, J., and Rehm, H. J. (1991). Degradation of pyrene by Rhodococcus sp. UW1. Appl. Microbiol. Biotechnol. 34, 671-676. doi: 10.1007/BF00167921

Wang, Q., Garrity, G. M., Tiedje, J. M., and Cole, J. R. (2007). Naïve Bayesian classifier for rapid assignment of rRNA sequences into the new bacterial taxonomy. Appl. Environ. Microbiol. 73, 5261-5267. doi: 10.1128/aem.00062-07

Wegner, K. M., Volkenborn, N., Peter, H., and Eiler, A. (2013). Disturbance induced decoupling between host genetics and composition of the associated microbiome. BMC Microbiol. 13:252. doi: 10.1186/1471-2180-13-252

Wongwongsee, W., Chareanpat, P., and Pinyakong, O. (2013). Abilities and genes for PAH biodegradation of bacteria isolated from mangrove sediments from the central of Thailand. Mar. Pollut. Bull. 74, 95-104. doi: 10.1016/j.marpolbul.2013.07.025

Yrjälä, K., Keskinen, A. K., Akerman, M. L., Fortelius, C., and Sipila, T. P. (2010). The rhizosphere and PAH amendment mediate impacts on functional and structural bacterial diversity in sandy peat soil. Environ. Pollut. 158, 1680-1688. doi: 10.1016/j.envpol.2009.11.026

Yuan, H., Yao, J., Masakorala, K., Wang, F., Cai, M., and Yu, C. (2014). Isolation and characterization of a newly isolated pyrene-degrading Acinetobacter strain USTBX. Environ. Sci. Pollut. Res. 21, 2724-2732. doi: 10.1007/s11356-013-2221-9

Zhang, Y., Qin, F. J., Qiao, J., Li, G. M., Shen, C. H., Huang, T. W., et al. (2012). Draft genome sequence of Rhodococcus sp. strain P14, a biodegrader of highmolecular-weight polycyclic aromatic hydrocarbons. J. Bacteriol. 194, 3546-3546. doi: $10.1128 /$ jb.00555-12

Zhou, J. Z., Xue, K., Xie, J. P., Deng, Y., Wu, L. Y., Cheng, X. L., et al. (2012). Microbial mediation of carbon-cycle feedbacks to climate warming. Nat. Clim. Chang. 2, 106-110. doi: 10.1038/nclimate1331

Conflict of Interest Statement: The authors declare that the research was conducted in the absence of any commercial or financial relationships that could be construed as a potential conflict of interest.

Received: 23 September 2014; accepted: 08 January 2015; published online: 30 January 2015.

Citation: Ren G, Ren W, Teng Y and Li Z (2015) Evident bacterial community changes but only slight degradation when polluted with pyrene in a red soil. Front. Microbiol. 6:22. doi: $10.3389 /$ fmicb.2015.00022

This article was submitted to Terrestrial Microbiology, a section of the journal Frontiers in Microbiology.

Copyright (C) 2015 Ren, Ren, Teng and Li. This is an open-access article distributed under the terms of the Creative Commons Attribution License (CC BY). The use, distribution or reproduction in other forums is permitted, provided the original author(s) or licensor are credited and that the original publication in this journal is cited, in accordance with accepted academic practice. No use, distribution or reproduction is permitted which does not comply with these terms. 